\title{
Tratamento cirúrgico de alopecia cicatricial no couro cabeludo e defeito da calota craniana em criança, sem transfusões de sangue
}

\author{
Surgical treatment of cicatricial alopecia in the scalp and cranial bone defect in a \\ child without blood transfusion
}

Juan Carlos Montano

PEDROSO $^{1}$

SANDRO SALANITRI $^{2}$

Américo Helene Júnior ${ }^{3}$

Trabalho realizado na Disciplina de Cirurgia Plástica do

Departamento de Cirurgia da Irmandade da Santa Casa de Misericórdia de São Paulo, São Paulo, SP, Brasil.

Artigo submetido pelo SGP (Sistema de Gestão de Publicações) da RBCP.

Artigo recebido: 25/7/2009 Artigo aceito: 22/9/2009

\begin{abstract}
RESUMO
Introdução: As Testemunhas de Jeová são um grupo religioso que não aceita as transfusões de sangue. Relato do Caso: Os autores descrevem o caso de uma criança, Testemunha de Jeová, que apresentava alopecia cicatricial no couro cabeludo e defeito da calota craniana, resultantes de politraumatismo. O tratamento foi iniciado com a colocação de expansor no couro cabeludo e uso de eritropoetina e sulfato-ferroso para aumento dos níveis de hemoglobina. A retirada do expansor e a correção do defeito da calota craniana com placa de acrílico foram realizadas com sucesso e sem o emprego de transfusões de sangue.
\end{abstract}

Descritores: Testemunhas de Jeová. Alopecia. Expansão de tecido. Transfusão de sangue. Eritropoetina.

\section{ABSTRACT}

Introduction: Jehovah's witnesses are a religious group that refuses blood transfusion. Case Report: The authors describe a case of a child who was a Jehovah's Witness and presented cicatricial alopecia in the scalp and cranial bone defect caused by a polytraumatism. The treatment was initiated with the introduction of tissue expander in the scalp and the use of erythropoietin and ferrous sulfate to increase the hemoglobin levels. The removal of the tissue expander and the correction of the cranial bone defect with an acrylic plate were done with success and without blood transfusion.

Keywords: Jehovah's witnesses. Alopecia. Tissue expansion. Blood transfusion. Erythropoietin.

\section{INTRODUÇÃO}

Realizar a correção cirúrgica de alopecia cicatricial no couro cabeludo e de defeito da calota craniana em uma criança sem transfusão de sangue pode constituir um desafio para os cirurgiões.

Embora as transfusões de sangue sejam utilizadas há décadas, recentemente o adequado papel da transfusão de sangue no manejo da anemia tem sido questionado ${ }^{1}$. Os cirurgiões estão cônscios não somente dos riscos associados às transfusões de sangue, mas também dos custos e suprimentos restritos das bolsas de sangue. Também há pacientes que devido a vários motivos, inclusive religiosos, não aceitam transfusões de sangue ${ }^{2}$. Tais fatores têm contribuído para a popularização de estratégias terapêuticas alternativas às transfusões de sangue, comumente denominadas de "gerenciamento e conservação do sangue". Tais princípios não deveriam limitar-se apenas ao tratamento das Testemunhas de Jeová, para as quais as transfusões de sangue não são uma opção terapêutica, mas deveriam constituir numa parte integral do dia-a-dia do cirurgião.

1. Cirurgião Plástico, Título de Especialista em Cirurgia Plástica da Sociedade Brasileira de Cirurgia Plástica (SBCP), Membro associado da SBCP, São Paulo, SP, Brasil.

2. Mestre em Medicina pela Faculdade de Ciências Médicas da Santa Casa de São Paulo, Membro Titular da SBCP, Médico Voluntário da Santa Casa de São Paulo, São Paulo, SP, Brasil.

3. Doutor em Medicina pela Faculdade de Ciências Médicas da Santa Casa de São Paulo, Membro Titular da SBCP, Chefe do Serviço de Cirurgia Plástica da Santa Casa de São Paulo, São Paulo, SP, Brasil. 
A reconstrução de defeitos do couro cabeludo é necessária em casos de trauma agudo, extirpação de tumores e melhora de cicatrizes inestéticas e alopecia. A utilização de expansão tecidual deve ser considerada especialmente nas lesões mais extensas, em que o uso de retalhos locais seja inadequado devido ao tamanho do defeito ou tecido local traumatizado ${ }^{3}$.

Os autores apresentam relato de caso de tratamento cirúrgico de alopecia cicatricial no couro cabeludo, com expansão tecidual e correção de defeito da calota craniana, em criança Testemunha de Jeová, com emprego de estratégias alternativas às transfusões de sangue.

\section{RELATO DO CASO}

B.L.A, 9 anos, sexo masculino, Testemunha de Jeová, vítima de politraumatismo aos 6 anos de idade por acidente automobilístico, com escalpelamento e fratura do crânio na região orbitofrontal direita, tratados com sutura da dura-máter nas bordas ósseas, desbridamento de tecidos desvitalizados e rotação de retalho local de couro cabeludo. Tratamentos alternativos à transfusão de sangue foram utilizados e o caso foi publicado na literatura ${ }^{4}$.

O paciente apresentava como sequelas, três anos após o politraumatismo, extensa alopecia cicatricial na região temporoparietal direita e frontal. A tomografia de crânio demonstrava pequena área cortical-subcortical hipoatenuante na região orbitofrontal direita de aspecto sequelar (Figura 1A). Em decorrência da grande extensão da alopecia cicatricial, optou-se pela expansão tecidual do couro cabeludo para sua correção. Estratégias alternativas às transfusões de sangue foram utilizadas por se tratar de paciente Testemunha de Jeová.

Com o paciente sob anestesia geral, foi realizada infiltração de solução de adrenalina 1:250.000, para reduzir o sangramento intraoperatório. Um expansor formato de rim de $480 \mathrm{ml}$ foi colocado no plano subgaleal através de uma incisão temporal direita e parietal direita. O nível de hemoglobina no pré-operatório era de $12,5 \mathrm{~g} / \mathrm{dl}$ e, no primeiro dia pós-operatório, diminuiu para $12,4 \mathrm{~g} / \mathrm{dl}$.

O paciente foi submetido à expansão tecidual do couro cabeludo, semanalmente, de maneira convencional, atingindo-se um volume de $660 \mathrm{ml}$ (Figura 1B). A fim de aumentar os níveis de hemoglobina para a segunda cirurgia, que apresentava maior potencial de sangramento, o paciente recebeu eritropoetina alfa na dose de $10000 \mathrm{UI}(300 \mathrm{UI} / \mathrm{kg}$ ), três vezes por semana, por via subcutânea, iniciando-se 4 semanas antes da data da cirurgia, totalizando 9 aplicações. A dosagem de ferritina sérica antes do início do tratamento com eritropoetina era de $107,7 \mathrm{ng} / \mathrm{ml}$, dentro dos valores de referência para sua idade, demonstrando adequado estoque de ferro no organismo. O nível de hemoglobina no início do tratamento com eritropoetina era de $12,4 \mathrm{~g} / \mathrm{dl}$. Suplemento de ferro elementar por via oral, na dose diária de $5 \mathrm{mg} / \mathrm{kg}$, e suplemento polivitamínico foram prescritos conjuntamente. Sete dias após o início do tratamento com eritropoetina e suplemento de ferro, já era observado aumento no número de reticulócitos. Ao término do tratamento, o nível de hemoglobina havia aumentado para 15,5 g/dl.
A segunda cirurgia foi realizada com o paciente sob anestesia geral, iniciando-se pela infiltração de solução de adrenalina 1:250.000. O expansor foi removido e as áreas de alopecia cicatricial foram retiradas. A equipe de neurocirurgia realizou o reparo do defeito orbitofrontal direito da calota craniana, com a colocação de uma placa de acrílico (Figura 1C). O retalho expandido de couro cabeludo foi avançado, permitindo a completa cobertura do defeito (Figura 1D). Um dia após a cirurgia, o nível de hemoglobina era de $12,1 \mathrm{~g} / \mathrm{dl}$. O paciente recebeu alta hospitalar no segundo dia pós-operatório, com ótima evolução (Figura 2).
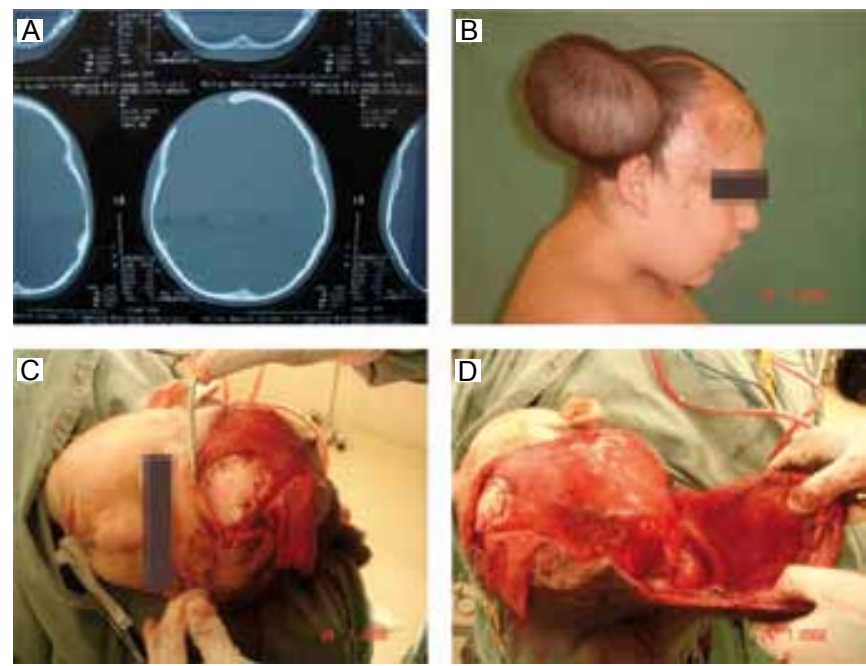

Figura 1 - A: Tomografia demonstrando sequela orbitofrontal direita;

B: Foto do paciente ao término da expansão do couro cabeludo;

C: Aspecto intraoperatório após colocação de placa de acrílico;

D: Retalho expandido de couro cabeludo antes de seu avanço.
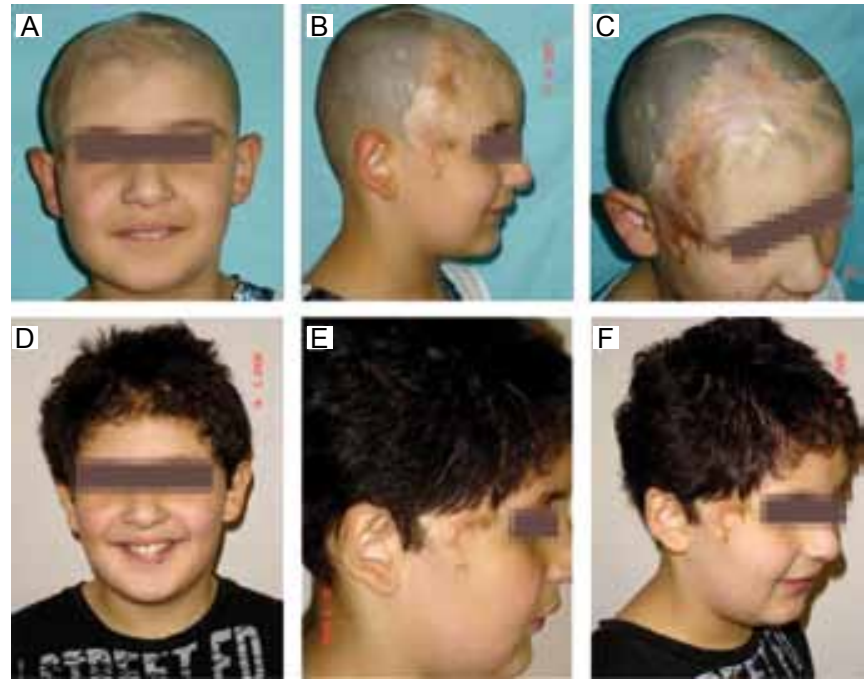

Figura 2 -Pré-operatório $(\boldsymbol{A}, \boldsymbol{B}$ e $\boldsymbol{C}) e$ pós-operatório $(\boldsymbol{D}, \boldsymbol{E} \boldsymbol{e} \boldsymbol{F})$ de 4 meses. 


\section{DISCUSSÃO}

"Gerenciamento e Conservação do Sangue" tem sido definido como "o uso apropriado do sangue e dos componentes do sangue, com o objetivo de minimizar seu uso" exposição dos pacientes às transfusões de sangue pode ser minimizada pelo uso sistemático de múltiplas técnicas de conservação do sangue, que envolvem o uso apropriado de medicamentos, equipamentos e técnicas cirúrgicas, de forma isolada ou associada.

Várias técnicas cirúrgicas e anestésicas foram desenvolvidas para reduzir as perdas sanguíneas, tais como: abordagens que reduzem o sangramento (endoscopia e laparoscopia); desenvolvimento de instrumentos cirúrgicos hemostáticos (eletrocautério, coagulador com raio de argônio) e materiais biológicos, como a cola de fibrina, que diminuem áreas de sangramento; infiltração de solução vasoconstritora; uso de medicamentos que estimulam a produção de plaquetas (IL-11 recombinante); drogas que reduzem a perda sanguínea intraoperatória, como os concentrados de complexo protrombínico e antifibrinolíticos (ácido tranexâmico); uso da desmopressina (reduz o sangramento em pacientes tratados com antiinflamatórios não esteroides antes da cirurgia); drogas que auxiliam na redução do sangramento agudo (Fator VIIa); anestesia com hipotensão controlada; hemodiluição normovolêmica aguda; recuperação intraoperatória de células; manutenção da normotermia (a hipotermia reduz a função plaquetária, aumentando o sangramento) ${ }^{5,6}$.

No caso relatado, a correção do defeito da calota frontal foi realizada com placa de acrílico, pela equipe de neurocirurgia, embora a indicação preferencial para esta cranioplastia seja o uso da tábua externa parietal retirada sem craniotomia. A cranioplastia com acrílico na região frontal pode originar osteomielite no longo prazo, pela proximidade com o seio frontal, quando este se desenvolver completamente. Além disso, o crescimento da calota craniana da criança pode provocar desestabilização da placa futuramente. A infiltração de solução vasoconstritora no couro cabeludo, tanto na cirurgia de colocação do expansor como na sua retirada, permitiu a diminuição do sangramento dos tecidos moles.

O conhecimento de que o organismo humano com anemia desenvolve mecanismos compensatórios (aumento do débito cardíaco, deslocamento da curva de dissociação da hemoglobina para a direita) que lhe permitem maior tolerância à anemia também contribui para reduzir as transfusões de sangue. Estudos demonstraram que hematócritos tão baixos como $20 \%$ foram bem tolerados por crianças hemodinamicamente estáveis ${ }^{4}$. No entanto, o avanço mais significativo para evitar as transfusões de sangue é reconhecidamente o uso da eritropoetina.

A eritropoetina é uma glicoproteína produzida pelos rins, que age diretamente nos progenitores das hemácias na medula óssea, estimulando a proliferação, diferenciação e maturação eritrocitária ${ }^{4}$. Existem diversos agentes estimuladores da eritropoiese aprovados em testes clínicos, com diferentes propriedades farmacocinéticas e farmacodinâmicas. Podendo ser administrada por via subcutânea, a eritropoetina promove, em três dias, aumento do número de reticulócitos, e o equivalente a uma bolsa de sangue é produzido em 7 dias, e 5 bolsas de sangue, em 28 dias. O estímulo da eritropoiese pela eritropoetina independe da idade ou do gênero. O intervalo de tempo pré-operatório necessário para o estímulo adequado da eritropoiese é de cerca de 4 semanas ${ }^{7}$.

A eritropoetina tem sido usada com sucesso, evitando-se transfusões de sangue em vários procedimentos cirúrgicos com diversas recomendações de dosagem, como $300 \mathrm{UI} / \mathrm{kg}$, três vezes por semana, durante 3-4 semanas e de 200 a 600 UI/ $\mathrm{kg}$, uma vez por semana, por quatro semanas ${ }^{7}$. Recomenda-se a verificação de um adequado ferro de depósito no organismo antes do início do tratamento com eritropoetina por meio da dosagem de ferritina sérica (ferritina acima de $100 \mathrm{ng} / \mathrm{ml}$ indica adequado ferro de depósito). Suplementação de ferro, folato e vitaminas B6, B12 e C são recomendados durante a terapia com eritropoetina, a fim de acelerar a resposta eritropoiética e evitar a depleção dos estoques de ferro. Embora neste relato de caso a estimulação da eritropoiese tenha sido realizada com eritropoetina e ferro oral, a literatura tem demonstrado a superioridade do ferro endovenoso em associação com a eritropoetina (ferro endovenoso 200 mg duas vezes por semana $)^{8}$. Para a administração de ferro endovenoso, recomenda-se a diluição de $100 \mathrm{mg}$ de ferro para $100 \mathrm{ml}$ de solução salina isotônica e uma infusão lenta (1 ml por minuto).

Dentre os possíveis efeitos colaterais da eritropoetina, a literatura cita sintomas gripais autolimitados, hipertensão, reação anafilática, hipercalemia, trombocitose e trombose; raramente relatados ${ }^{4}$. A eritropoetina é contraindicada nos casos de hipersensibilidade à mesma, hipertensão arterial maligna, gravidez e lactação. A eritropoetina não apresenta interação medicamentosa clinicamente significativa e a segurança de seu uso em pacientes submetidos a procedimentos cirúrgicos tem sido demonstrada pela distribuição semelhante de efeitos adversos, inclusive eventos trombóticos, em pacientes tratados com eritropoetina ou placebo, em mais de 1000 pacientes participantes de ensaios clínicos?

Várias são as complicações associadas às transfusões de sangue e até mesmo seus benefícios têm sido questionados. Uma revisão sistemática da literatura com metanálise, avaliando a eficácia das transfusões de sangue em pacientes críticos, foi recentemente publicada ${ }^{9}$. As revisões sistemáticas com metanálise são o tipo de estudo de maior evidência científica $^{10}$. Esta revisão sistemática incluiu 45 estudos, compreendendo mais de 270 mil pacientes que foram divididos em diferentes grupos: vítimas de trauma, cirurgia geral, 
cirurgia cardíaca, entre outros. Dos 45 estudos avaliados, 42 demonstraram que os riscos das transfusões de sangue eram maiores que os benefícios (aumento de infecção, aumento de mortalidade), dois foram neutros e apenas um único estudo mostrou benefício num subgrupo específico de pacientes. Os autores da revisão concluem que as transfusões de sangue estão associadas a aumento da morbidade e mortalidade e que, portanto, as práticas atuais de transfusão de sangue precisam ser reavaliadas ${ }^{9}$.

\section{CONCLUSÃO}

A literatura tem demonstrado que procedimentos cirúrgicos podem ser realizados sem transfusão de sangue de forma segura, com uma preparação pré-operatória adequada. Diante da maior preocupação por parte dos cirurgiões em relação a eficácia, riscos, custos e suprimentos restritos das bolsas de sangue, os princípios de gerenciamento e conservação do sangue devem constituir numa parte integral do dia-a-dia do cirurgião. Várias são as estratégias alternativas à transfusão de sangue que podem ser empregadas em todos os pacientes, inclusive no tratamento das Testemunhas de Jeová, sendo uma das mais importantes a eritropoetina humana recombinante, utilizada neste relato de caso.

\section{AGRADECIMENTOS}

Os autores agradecem ao Dr. Fernando José Cabral, membrodaSocietyfor the AdvancementofBloodManagement
(SABM), pela ampla revisão bibliográfica exigida pelo presente trabalho.

\section{REFERÊNCIAS}

1. Goodnough LT, Shander A. Blood management. Arch Pathol Lab Med. 2007;131(5):695-701.

2. Gohel MS, Bulbulia RA, Slim FJ, Poskitt KR, Whyman MR. How to approach major surgery where patients refuse blood transfusion (including Jehovah's Witnesses). Ann R Coll Surg Engl. 2005;87(1):3-14.

3. Radwanski HN, Almeida MWR, Aguiar LFS, Altenhofen MS, Pitanguy I. Algoritmo para as alopécias cicatriciais e suas opções de tratamento. Rev Bras Cir Plást. 2009;24(2):170-5.

4. Digieri LA, Pistelli IP, Carvalho CE. The care of a child with multiple trauma and severe anemia who was a Jehovah's Witness. Hematology. 2006;11(3):187-91.

5. Centeno RF, Long CD, Granick MS. Elective plastic surgery in a Jehovah's Witness: a case series and review of the literature. Ann Plast Surg. 2000;45(3):244-51.

6. Shander A. Surgery without blood. Crit Care Med. 2003;31(12 Suppl):S708-14.

7. Goodnough LT, Monk TG. Erythropoietin therapy in the perioperative setting. Clin Orthop Relat Res. 1998;(357):82-8.

8. Rohling RG, Zimmermann AP, Breymann C. Intravenous versus oral iron supplementation for preoperative stimulation of hemoglobin synthesis using recombinant human erythropoietin. J Hematother Stem Cell Res. 2000;9(4):497-500.

9. Marik PE, Corwin HL. Efficacy of red blood cell transfusion in the critically ill: a systematic review of the literature. Crit Care Med. 2008;36(9):2667-74.

10. Goldenberg DC, Baroudi R. Medicina baseada em evidências: como e quando em cirurgia plástica? Rev Bras Cir Plást. 2009;24(1):I.

\section{Correspondência para:}

Juan Carlos Montano Pedroso

Av. Bem-te-vi, 362 - 84A - Moema - São Paulo, SP, Brasil - CEP 04524-030

E-mail: juancmontano@hotmail.com 